\title{
Analysis of Science and Technology Elements in The Application of STEAM Based Learning (Science, Technology, Engineering, Art, and Mathematics)
}

\author{
Nur Anisa \\ Early Childhood Education \\ Universitas Negeri Malang \\ Malang, Indonesia \\ nur.anisa.fip@um.ac.id
}

\author{
Retno Tri Wulandari \\ Early Childhood Education \\ Universitas Negeri Malang \\ Malang, Indonesia \\ retno.tri.fip@um.ac.id
}

\begin{abstract}
This study aims to describe the application of STEAM based learning (Science, Technology, Engineering, Art, and Mathematics) in the learning process especially in the elements of Science and Technology. This study is also to determine the extent of knowledge of teachers related to STEAM based learning. This type of research is qualitative research. This research was conducted at TK Negeri Pembina 01 Malang City. The data collection of the research was done by observation, interview, and documentation. The technique of analyzing data uses interactive analysis model. The result describes that the learning process in TK Negeri Pembina 01 Malang City which has shown some elements in STEAM based learning indirectly that is on the element of Science and Technology so that it can train the early childhood to think critically and have some techniques and designs to solve problem-based on science and technology.
\end{abstract}

Keywords - STEAM based learning, science, technology, early childhood education

\section{INTRODUCTION}

Indonesia is currently working to improve quality in various sectors, particularly in the Education sector. This is just because Indonesia is going to carry Indonesian Demographic Bonus out in 2025-2045. Demographic bonuses can be obtained when the current generation who are approximately 1-19 years old are equipped with knowledge that is in accordance with the demands of the times so that the young generation will become productive human resources. The spread of the tendency of the ASEAN Economic Community (AEC) also requires an increase in the quality of human resources that have competitiveness to meet the glory of Indonesia, so Indonesia is deemed necessary to instill science and technology-based economic education from an early age. Science and technology-based economic education are expected to realize humanity with character, noble character, scientific reasoning and a willingness to progress and develop.

STEAM's learning (Science, Technology, Engineering, Arts, and Mathematics) is a breakthrough for education in Indonesia that is trying to develop human resources to be able to create a science and technology-based economy. Through STEAM learning, children are invited to think comprehensively with problem-solving patterns based on the five elements in STEAM, namely: Science, Technology, Engineering, Arts, and Mathematics. STEAM-based learning aims to train children to think critically and have techniques or designs to solve problems in the world based on science and technology. STEM education is an interdisciplinary approach to learning academic concepts combined with realworld lessons where students apply science, technology, engineering, and mathematics in a context that makes the relationship between schools, communities, jobs and global companies possible to develop STEM literature so has the ability to compete in a new economy [1].

The teacher's problems is sometimes people think that STEAM is merely about art integration, because many science teachers may not have artistic training, or maybe not sure how to put "A" into STEM. Similar art instructors do not have a lens to understand where or how to build STEM into art. A broader and more inclusive view of STEAM that includes the scientific discipline needed, with an entry point in the entire context. This shows STEAM's related view of art integration, which focuses more on several principles: interdisciplinarity, creativity, genuine learning or the real world, and project-centered thinking [2].

STEAM can be used at various levels of education by adjusting the stage of child development. STEAM Education was created to educate children to be more aware of the hightech skills needed to expand the STEAM job market. Professionals in all fields are possible to realize children who are world competitive, but sometimes learning activities that have focused on STEAM, there are still graduates who do not have an innovative spirit and encouragement to advance their countries in the future. In the end, education must be about children and for children. The STEAM initiative offers children to have high-tech skills.

Complex systems and solutions are conceptualized and designed with dominant analytical skills but ultimately want to switch to applied and measurable capabilities that provide business/mission values that require more creative skills. The integration of art and science produces unique skills that can improve the results of this transition. Children are expected through STEAM to have the ability to simultaneously decipher complex problems by using convergent thinking and then applying solutions that suit the real world using different thoughts. Integrating art into the STEAM curriculum provides a pathway for the formation of personal meaning, self-motivation, and self-intuition. Children are able to build their own learning and continue STEAM in the future. 
At the PAUD level, STEAM is simple. STEAM is able to stimulate and encourage children's interest in the world of unlimited science and technology. Children will be trained to conduct a thorough analysis in order to make decisions. Children are also able to see things from various points of view and will be careful of the information they receive. STEAM also trains children to experiment with several experiments and enriches insights to always want to try so that eventually, children will grow into creative, initiative and innovative individuals.

STEAM's Conceptualization (Science, Technology, Engineering, Arts, and Mathematics) refers to the creation of a learning environment where children's curiosity about the world can develop through authentic and systematic investigations that utilize various design thinking skills. and scientific knowledge and processes. Early childhood educators can support authentic investigations with scaffolding using strategies for problem-solving and posing problems and adhere to a holistic approach to scientific thinking and reasoning. Children exploration and making meaning in children's knowledge is based on their real-world experience. Acquisition of basic skills in literacy and numeracy allows daily investigation. Therefore, STEAM's initial experiences (Science, Technology, Engineering, Arts, and Mathematics) involved children in order to obtain and use these basic skills appropriately, in meaningful contexts relevant to their daily lives [3].

Throughout the design thinking process, Katherine integrates two different ways to redesign. The curriculum makes children involved in problem-solving and creativity again to design the process as a mixture of creative/analytical. In developing this STEAM project, Katherine used the Stanford model of empathy, problem definition, ideation, prototyping, and testing. Empathy research conducted through informal interviews, observations, and surveys of children to understand their motivations and interests.

This helped him determine his problem, around creating a curriculum that allows children spend time in depth with the problem to make connections between disciplinary ideas and their own lives by keeping an idea journal to write ideas for a certain period of time, and use them for several things to stimulate brainstorming sessions with other teachers. The design process supports his thinking, to build STEAM-based lessons with several aspects of artistic, scientific, and social / humanities projects. For example, Katherine found a way to use empathy to help children understand the water crisis. Katherine performed a direct water experiment where the child was given a limited amount of clean water and had done so to decide how to use this water. While the child experimented, Katherine collected observations of their reactions, their choices, and their reaction to the use of dirty water, for bathing, drinking, and cooking. As Katherine noted in the reflection of the teacher's designer. This gives insight into the child's reactions and emotions to the problem of the water itself home and society [2].

Early Learning in Math and Science [4] argues about AUD science process skills. Science process skills also called practical science are skills used by scientists in the process of doing science. These skills are the same skills that we all use in our life when we try to find out questions every day and interact with the world in a scientific way. As for several stages of the scientific process:

\section{1) Observing (Observing)}

Science begins with observation. This is the first and most basic of the process of skill. Observing includes seeing, but also hearing, smelling, feeling, feeling (texture, temperature, etc.) and other sensory observations. By observing with their senses, children collect data about objects and phenomena. It is important to note that the ability to make good observations is very important for the development of other process skills. Observations are often recorded through notes or pictures.

\section{2) Asking questions (Asking Questions)}

Curiosity is the heart of scientific inquiry. Children naturally have a sense of curiosity and have a strong urge to ask questions to understand their world. By support from adults, children can begin to develop the skills of asking focused questions that allow it to proceed further with investigative science.

\section{3) Comparing and distinguishing (Comparing and} Contrasting)

Making observations naturally lead to making comparisons. Comparing and differentiating requires children to sharpen their observations and focus on details to identify similarities and differences. The process of comparing and differentiating skills is the basis of group making and classification.

\section{4) Classify (Classifying)}

Classification is the process by which children group and sort objects, people or events. To classify, children make comparisons between objects, noting their similarities and their differences. Small children can sort a set of objects if objects such as stones, leaves, seeds to subsets. They can sort properties such as color, size, shape, texture, float/sink, magnet / non-magnetic. Children must be given the opportunity to group the same set of items in different ways and make their own criteria for sorting.

\section{5) Predicting}

Children make predictions when they formulate an idea about what they think will happen in the future. A simple experiment involves a pre-pilot as a child, considering what will happen. Predictions are based on previous observations and experiences. Prediction helps develop awareness of cause and effect - "If we do it ... then what will happen?"

\section{6) Experiment (Experimenting)}

Small children can do simple experiments to get their ideas out (hypotheses). In early childhood, experiments often occur spontaneously, but with age, the teacher can help them so that they are wiser in planning their investigations. Experiment introducing children to the process of making hypotheses and identifying and controlling variables.

7) Using simple tools to observe and collecting information

Small children can use real tools such as a magnifying glass, thermometers, eyedroppers or pipettes, tweezers, measuring spoons and cups, binoculars, rulers, and balance scales expand their observations, to investigate and collect data. This tool they usually get and use from everyday experience, not only during the specified science time.

\section{8) Measurement (Measuring)}

Measuring is the quantification of a child's observation through a standard or nonstandard unit. Small children can 
measure length, volume, weight, temperature and time. Standard measurements include inches, feet, pounds, seconds, minutes or days. Non-standard measurements do not require children to understand how to use gauges such as squares, internodes, etc. In all cases, items used to measure need to be identical (eg new crayons) so that measurements are consistent.

\section{9) Drawing Conclusion (Concluding)}

Drawing conclusions are about processing and interpreting observations and results from experiments. Because early conclusions of young children are often based on their own limited personal observation and prior knowledge, their theories are often wrong. A concept may take years to be developed by a child so adults continue to encourage children to share their explanations. Provides additional learning experience to stimulate knowledge and develop children's concepts.

\section{0) Communicating (Communications)}

Communication requires a child to gather information, process it, and then present it so that others can understand it. Children can convey their observations, ideas, and conclusions by speaking or writing, visually in other media images and art, or through dramatic representations.

\section{1) Using and Making Models (Designing)}

Scientists use models in many ways to help them communicate their ideas and to understand the process. A model is created simpler or easier to see/observe directly. For example, a globe is an earth model. Every model is like a real thing in several ways and different from the real thing in several ways. Models can help children learn something that cannot be observed directly. Children can also build their own models of things like trees, rockets, flowers, etc.

STEAM (Science, Technology, Engineering, Arts, and Mathematics) in early childhood is done by building a school-home-community partnership that gives children the opportunity to be involved in authentic scientific exploration and mathematical thinking, both as fields of study with rights themselves, and as a component of a holistic approach to children's learning that does not separate experience into content areas. Educators should create space for children to experience STEAM (Science, Technology, Engineering, Arts, and Mathematics) in art, reading, and society.

This includes exposing all children to the concepts, vocabulary, and experiences that accompany STEAM's (Science, Technology, Engineering, Arts, and Mathematics) activities that are strong and in line with development and prepare their teachers to support this effort. Technology can support this goal to ensure that widespread access is the reality, and that high-quality content that is consistent with the learning objectives and children available development trajectories consistently.

Good early learning is STEAM learning. Children experience the world as a whole, and the experience of early childhood education should not impose the whole into isolated pieces. Instead, teachers must build opportunities that can offer technology to support an inclusive approach to STEAM in all fields including art, literacy and social studies. Technology is used to contribute to the development of language and children's vocabulary in all fields by providing a strong model and context for language use that reaches children and adults in their lives.
Researchers made preliminary observations of the Malang City Trustee Kindergarten which was the preeminent kindergarten in Malang City. The institution offers a variety of learning models and facilities to make it the most favorite kindergarten institution in the area. The results of preliminary observations showed several elements in STEAM learning, especially Science and Technology in its learning. Therefore, researchers wanted to explore more about the application of STEAM-based learning, especially Science and Technology in the Kindergarten.

\section{METHOD}

This research uses descriptive research. This study is intended to describe the application of STEAM-based learning (Science, Technology, Engineering, Arts, and Mathematics) in Kindergarten. The approach used in this study is a qualitative approach. This research is aimed more at the purpose of obtaining in-depth and meaningful data studies. This qualitative method is used for the purpose of obtaining in-depth and meaningful data related to the application of STEAM-based learning (Science, Technology, Engineering, Arts, and Mathematics) in Kindergarten.

Data collection techniques used in this study consist of observation, interviews, and documents. Observations were made on STEAM-based learning processes (Science, Technology, Engineering, Arts, and Mathematics) in Kindergarten. Interviews were conducted on several respondents and informants to strengthen the data, namely: principals, teachers, parents or people around the school (significant others). Documentation and archives used in data collection in this study include curriculum documents, photographs, and recordings during the research. Data validity in this study uses source triangulation, review of key informants (member checking) and audit techniques. The data analysis technique used in this study is the interactive analysis model Miles and Huberman.

\section{RESULT AND DISCUSSION}

The results of the study are presented based on the results of observations, interviews, and documentation during the study. The results and discussion of this study include an overview of the elements of Science and Technology in the application of STEAM-based learning that is indirectly in the learning process in TK Negeri Pembina 01 Malang City. This was indicated by several learning activities that included elements of science such as experimenting with color mixing, plant growth, water absorption and (simple capillarity).

All science thinking processes are shown in these learning activities. In line with the science thinking process according to [5] the results of the study indicate that the scientific thinking process occurs in 5 stages, namely:

\section{1) Observing what happens}

This can be seen when the child starts observing in plant growth activities. The teacher invites children to see plants around the child's school. The teacher stimulates the child to observe some of these plants. After that, the teacher asks the child what they see. Children begin to respond to answers to teacher questions. The teacher asks some of these questions only to some children in one class related to what they see.

\section{2) Classify or regulate information;}


The results showed that when the research the teacher asked questions about the differences in the plants that the children had observed. Children are stimulated to be able to give their opinions regarding differences that arise.

\section{3) Predict what will happen;}

The results showed that when the research the teacher gave questions about the child related to the prediction of what would happen when the plants were given various treatments. Children give good answers.

\section{4) Testing predictions to see the truth;}

The results show that after the child predicts the child is invited to experiment to test predictions by seeing the truth. The experiment they carried out was planting green bean seeds, planting cuttings of cassava, planting corn, and rose cuttings. Plants are treated with light and not. Experiments last for several days. Day after day the plants begin to show their growth. Children are asked every day to observe the plants they plant before they enter the classroom and take lessons. Children are given the opportunity to ask questions regarding the development of their plants every day.

\section{5) Draw conclusions}

At the end of the scientific thinking process, there is a conclusion. At this time the child's pattern of thinking strongly shows the development of his brain. Children begin to find things and build their own concepts of knowledge based on their experiences.

Then, the technology element is shown when children learn by utilizing tablets, laptops, and LCD projectors in their daily learning. The video was played in the form of the growth process of mung bean plants, cassava plants, corn, etc. Videos are usually played after children learn from their surroundings. For example, observing the plants around it. Utilization of technology besides teaching children drawing is allowed to use tablets to draw plants. It indirectly teaches children to develop their fine motor development.

\section{CONCLUSION}

Conclusions from this study are as follows: Learning process in TK Negeri Pembina 01 Malang City has indirectly implemented STEAM-based learning, especially elements of science and technology. This is shown in various ways activities that lead children to think critically through the process of thinking science by utilizing existing technology. In this study, the teacher provides a stimulus to children to learn to develop the concept of knowledge through children's experience. But during the study, the teacher did not give the child freedom so that the advice that could be done was to deliberately not give instructions to choose what plants the child would observe. Thus the child will be more aware of ideas, thoughts, and a sense of responsibility for his choices and the child will tend to feel freer and not burdened during the learning process.

\section{REFERENCES}

[1] Pennsylvania STEM Network, Southwest Region, Long Range Plan (2009-2018), Plan Summary,

http://www.cmu.edu/gelfand/documents/stem-survey-report-cmuiu1.pdf.

[2] Henriksen, Danah (2017) "Creating STEAM with Design Thinking: Beyond STEM and Arts Integration,"The STEAM Journal: Vol. 3: Iss. 1, Article 11. DOI: 10.5642/steam.20170301.11.

[3] Soylu, Şebnem. (2016). STEM EDUCATION IN EARLY CHILDHOOD IN TURKEY. Journal of Educational and Instructional Studies in The World. Volume: $6 \mathrm{~J}$

[4] Early Learning in Math and Science (ELMS). 2017. Science Process Skills in Early Childhood. USA: The Regents of the University of California.

[5] Margaret. 2005. Helping Your Child: Learn Science. Washington: Education Publications Center. 